\title{
First evidence of heteroplasmy in Grey Partridge (Perdix perdix)
}

\author{
Claudia Pizzirani ${ }^{1}{ }^{12}$, Paolo Viola ${ }^{2}$, Federica Gabbianelli ${ }^{3}$, Anna Fagotti ${ }^{1}$, Francesca Simoncelli ${ }^{1}$, Ines Di Rosa ${ }^{1}$, \\ Paolo Salvi ${ }^{4}$, Andrea Amici ${ }^{2}$ and Livia Lucentini ${ }^{1 *}$ (I)
}

\begin{abstract}
We report for the first time the occurrence of heteroplasmy in Grey Partridge (Perdix perdix) revealed by means of two mitochondrial fragments. The possible serious biological and management implications of this exception to unilateral inheritance of mtDNA were underlined.
\end{abstract}

Keywords: Galliformes, Grey Partridge, Heteroplasmy, Hybridization, Perdix perdix

\section{Correspondence}

The Grey Partridge (Perdix perdix Linnaeus, 1758) is a polytypic Galliform species included in the Least Concern (LC) category of the IUCN Red List of Threatened Species at both global (Staneva and Burfield 2017) and national scale (Peronace et al. 2012). Considering that, to date, Grey Partridge's population genetics is based on mtDNA (Andersen and Kahlert 2012), and that heteroplasmy has been previously described specifically in hybrids and other Galliform species (Barr et al. 2005; Gandolfi et al. 2017), we decided to investigate the presence of this phenomenon in $P$. perdix.

During this research, both wild and farm animals were analyzed (102 samples, Additional file 1); as concerns wild animals, both present and historical (see Gandolfi et al. 2017 for "historical" definition), P. perdix samples were characterized, whereas as to contemporary live samples, non-invasive specimens belonged both to husbandries or were sampled in nature (feather or faeces).

DNA was extracted through a specifically modified protocol (Lucentini et al. 2010), and two mitochondrial genes, Cytochrome Oxidase Subunit I (COI) and Control Region (CR/D-loop), were amplified (Kerr et al.

*Correspondence: livia.lucentini@unipg.it

${ }^{1}$ Department of Chemistry, Biology and Biotechnologies (DCBB), University of Perugia, 06100 Perugia, Italy

Full list of author information is available at the end of the article
2007; Barbanera et al. 2009) and Sanger sequencing was outsourced for both ends of amplicons to Eurofins Genomics.

All sequences of $561 \mathrm{bp}$ for D-loop and of $334 \mathrm{bp}$ for COI were screened manually looking for double peaks in order to evaluate the presence and to validate point heteroplasmy (Ramos et al. 2013). We found out that, out of 102 individuals, nine showed point heteroplasmy in the D-loop fragment (Fig. 1A), and two in COI gene. Both mutations are missense, causing in the first case the substitution of an Isoleucine (AUU) by a Serine (AGU) while in the other case a Glycine (CAA) was substituted by an Arginine (CGA).

Different haplotypes were retrieved and deposited in GenBank (Accession Numbers MN413488-MN413500, MT649222-MT649228 for D-loop and MN480303MN480304, MT649229-MT649247 for COI).

Specimens presenting clear heteroplasmic D-loop single mutation sites and others showing electropherograms suggesting D-loop heteroplasmy insertion/deletion, were cloned using pGEM-T Easy vector (Promega) following the manufacturer's instructions. The analysis of clones strongly confirms the presence of heteroplasmy and the absence of any contamination. In fact, obtained clones, when sequenced, showed two different haplotypes, confirming the presence of more than one mtDNA in each cloned sample (Fig. 1B). 


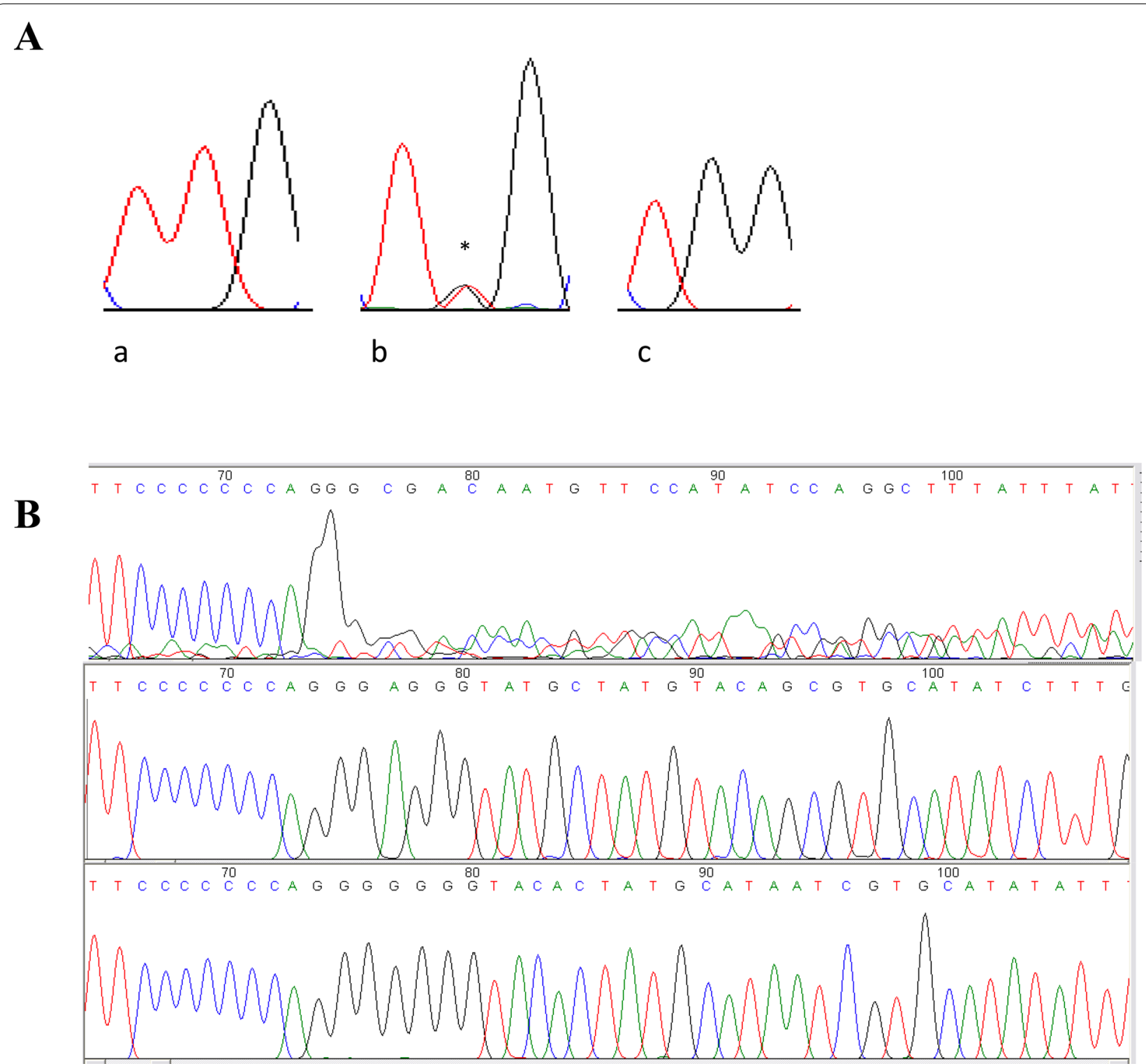

Fig. 1 A Example of D-loop heteroplasmy in Perdix samples. Example of polymorphic site (b) (GenBank MN413492), clearly showing mtDNA heteroplasmy compared with homoplasmic samples for this site (a) (GenBank MN413497) (c) (GenBank MN413494). B Electropherogram of one of the cloned samples and of two related clones (MN413488-MN413489)

Furthermore, to rule out possible contaminations, 39 individuals, including the nine heteroplasmic ones, were genotyped with a nuclear gene, the Oocyte maturation factor (c-mos) using both primers appropriately designed for this purpose (CMOS2F; F5'-3'GCTGTG AAGCAAGTGAAGAA; CMOS2 R; R5'-3'AGCCGA AGTCTCCAATCTT) and those described by Shen et al. (2014). The analysis of this nuclear locus never showed any double peaks and/or signal superimposition, thus excluding the presence of sample contamination.
Obtained related sequences were registered in GenBank (MN442418-MN442421).

In conclusion, this study provides the first evidence of mitochondrial heteroplasmy in Perdix perdix, a phenomenon that can create some ambiguities in phylogenetic and evolutionary interpretations. In fact, paternal mtDNA could lead to inaccurate estimates of divergence times if the molecular clock is used, and could confuse the putative haplogroup assignment. Furthermore, the data obtained, suggesting the occurrence of hybridization in Perdix perdix, strongly underlined the importance of 
the rapid adoption of control measures aimed to prevent the introduction of genomes from different geographical areas and to avoid the concrete risk of an extinction vortex to which the residual, small and isolated populations are segregated.

Further researches should focus to advance the knowledge on the hybridization scheme of Perdix species and on the possible interfertile species, to better understand the evolutionary history of the species and its management.

\section{Supplementary information}

Supplementary information accompanies this paper at https://doi. org/10.1186/s40657-020-00213-w.

Additional file 1. Data about samples used in this study.

\section{Acknowledgements}

Authors would like to thank the Natural History Museum of the University of Pisa, the Civic Museum of Zoology of Rome, the Casalina's Gallery of Natural History and the Natural History Museum of Fisiocritici of Siena.

\section{Authors' contributions}

$A A, P V$ and $L L$ conceived and designed the research. PV, PS and AA acquired samples. CP, FG and LL performed the sample analysis. LL, AF and AA analyzed the data. PV, LL, CP, FS, IDR and AA conducted manuscript preparation, revising and analysis of intellectual contents. LL and AA contributed equally to the extent of this research. All authors read and approved the final manuscript.

\section{Funding}

Not applicable.

\section{Availability of data and materials}

Sample number and origin of each sample was reported. In particular a geographical origin or a museum/collection collocation was specified, if applicable. Furthermore, details about GenBank code on D-Loop, COI and c-mos fragment were provided. Different haplotypes were retrieved and deposited in GenBank (Accession Numbers MN413488-MN413500, MT649222-MT649228 for Dloop, MN480303-MN480304, MT649229-MT649247 for COI and MN442418-MN442421 for c-mos).

\section{Ethics approval and consent to participate}

The performed sampling procedures and analyses are consistent with the Directive 2010/63/EU, the Italian national regulations and the indications of the Ethics Committee of the Universities of Perugia and Viterbo (Italy). The approval by the Ethics Committee was not necessary because of the nature of the samples (museal individuals) and of the non-invasive in vivo sampling method. In fact, just two feathers were collected from live animals excluding those having a functional role. Birds were immediately released at the same sampling site. The sampling campaign was authorized by local authorities with the scientific ISPRA authorization number 12184.
Consent for publication

Not applicable.

\section{Competing interests}

The authors declare that they have no competing interests.

\section{Author details}

${ }^{1}$ Department of Chemistry, Biology and Biotechnologies (DCBB), University of Perugia, 06100 Perugia, Italy. ${ }^{2}$ Department of Agriculture and Forest Science (DAFNE), University of Tuscia, 01100 Viterbo, Italy. ${ }^{3}$ Department for Innovation in Biological Agro-food and Forest Systems (DIBAF), University of Tuscia, 01100 Viterbo, Italy. ${ }^{4}$ Parco Nazionale dei Monti Sibillini, 62039 Visso, MC, Italy.

Received: 16 April 2020 Accepted: 22 July 2020

Published online: 02 August 2020

\section{References}

Andersen LW, Kahlert J. Genetic indications of translocated and stocked grey partridges (Perdix perdix): does the indigenous Danish grey partridge still exist? Biol J Linn Soc. 2012;105:694-710.

Barbanera F, Guerrini M, Khan AA, Panayides P, Hadjigerou P, Sokos C, et al. Human-mediated introgression of exotic chukar (Alectoris chukar, Galliformes) genes from East Asia into native Mediterranean partridges. Biol Invas. 2009;11:333-48.

Barr CM, Neiman M, Taylor DR. Inheritance and recombination of mitochondrial genomes in plants, fungi and animals: Research review. New Phytol. 2005; 168:39-50.

Gandolfi A, Crestanello B, Fagotti A, Simoncelli F, Chiesa S, Girardi M, et al. New evidences of mitochondrial DNA heteroplasmy by putative paternal leakage between the Rock Partridge (Alectoris graeca) and the Chukar Partridge (Alectoris chukar). PLoS ONE. 2017;12:e0170507.

Kerr KCR, Stoeckle MY, Dove CJ, Weigt LA, Francis CM, Hebert PDN. Comprehensive DNA barcode coverage of North American birds. Mol Ecol Notes. 2007;7:535-43.

Lucentini L, Gigliarelli L, Puletti ME, Volpi L, Panara F. Comparison of conservative DNA extraction methods for two Galliformes: grey partridge (Perdix perdix italica, Hartert 1917) and red-legged partridge (Alectoris rufa, Linnaeus 1758). Conserv Genet Resour. 2010;2:381-4.

Peronace V, Cecere J, Gustin M, Rondinini C. Lista rossa degli uccelli nidificanti in Italia. Avocetta. 2012;36:11-58.

Ramos A, Santos C, Mateiu L, del Mar Gonzalez M, Alvarez L, Azevedo L, et al. Frequency and pattern of heteroplasmy in the complete human mitochondrial genome. PLOS ONE. 2013;8:e74636.

Shen Y-Y, Dai K, Cao X, Murphy RW, Shen X-J, Zhang Y-P. The updated phylogenies of the Phasianidae based on combined data of nuclear and mitochondrial DNA. PLoS ONE. 2014;9:e95786.

Staneva A, Burfield I. European birds of conservation concern. Populations, trends and national responsibilities. Cambridge: BirdLife International; 2017. p. 170.

Ready to submit your research? Choose BMC and benefit from:

- fast, convenient online submission

- thorough peer review by experienced researchers in your field

- rapid publication on acceptance

- support for research data, including large and complex data types

- gold Open Access which fosters wider collaboration and increased citations

- maximum visibility for your research: over 100M website views per year

At BMC, research is always in progress.

Learn more biomedcentral.com/submissions 